\title{
DISPERSÃO DE ORTHEZIA PRAELONGA DOUGLAS, 1891 (HEMIPTERA: ORTHEZIIDAE) CAUSADA POR EQUIPAMENTOS DE PULVERIZAÇÃO EM POMAR DE CITROS ${ }^{1}$
}

\author{
ODAIR APARECIDO FERNANDES ${ }^{2}$, TATIANA RODRIGUES CARNEIRO ${ }^{2}$, ANIELE PIANOSCKI DE CAMPOS ${ }^{2}$, \\ THAIS TANAN DE OLIVEIRA ${ }^{2}$, MARCELO DA COSTA FERREIRA ${ }^{2}$
}

\begin{abstract}
RESUMO-A cochonilha O. praelonga é considerada uma importante praga dos citros no Brasil, e informações sobre a sua dispersão estão baseadas apenas em observações empíricas. Objetivou-se avaliar o efeito de equipamentos de pulverização comumente utilizados pelos citricultores na dispersão da praga. Armadilhas adesivas foram instaladas no solo e em vergalhões dispostos verticalmente às plantas de três linhas adjacentes em um talhão de citros contendo plantas infestadas pela praga. Foram adotados equipamentos utilizados para controle de pragas dos citros. A avaliação da dispersão foi realizada por meio da contagem de fêmeas, ninfas ou partes dos insetos aderidas às armadilhas adesivas. Os equipamentos Martignani e Bié foram capazes de lançar a praga a até $15 \mathrm{~m}$, enquanto, para o equipamento Turbo Valência, detectaram-se fragmentos cerosos a até $22 \mathrm{~m}$ da máquina. Os equipamentos dotados de pistola não causaram qualquer dispersão da praga. Portanto, evidenciou-se que mesmo a utilização de equipamentos para controle de outras pragas pode favorecer a dispersão da cochonilha $O$. praelonga em pomares de citros, e isso deve ser considerado no aprimoramento do programa de manejo integrado de pragas dos citros.
\end{abstract}

Termos para indexação: ortézia; disseminação de pragas; cochonilha; manejo integrado de pragas.

\section{DISPERSAL OF ORTHEZIA PRAELONGA DOUGLAS, 1891 (HEMIPTERA: ORTHEZIIDAE) CAUSED BY SPRAYERS IN CITRUS ORCHARD}

\begin{abstract}
The scale $O$. praelonga is an important citrus pest in Brazil and information on its dispersal is based solely on empiric observation. This aim of this work was to evaluate the effect of citrus spraying equipments on the dispersal of the pest. Stick traps were placed on the ground as well as on metal posts at three adjacent rows of citrus plants. The citrus area presented some highly infested plants. Sprayers usually adopted to control pest in citrus orchards were evaluated. The evaluation consisted on counting females, nymphs or parts of the insects adhered to the stick traps. The equipments Martignani and Bié were capable of blowing the insect as far as $15 \mathrm{~m}$. However, Turbo Valência blew waxy parts as far as $22 \mathrm{~m}$ from the machine. Equipments with spray guns did not cause insect dispersal. Therefore, even equipments used to control other citrus pests can favor the dispersal of $O$. praelonga in citrus orchards. This should be carefully considered to improve the current citrus pest management program
\end{abstract}

Index terms: Orthezia; pest dissemination; citrus scale; integrated pest management.

\section{INTRODUÇÃO}

A cochonilha Orthezia praelonga Douglas, 1891 (Hemiptera, Ortheziidae), nativa da América Tropical (Gonçalves \& Cassino, 1978), é considerada praga importante no Brasil desde 1954, quando foi responsável por grandes perdas na citricultura carioca. Naquela ocasião, a praga ocasionou perdas na produção de citros estimadas entre 50 e $90 \%$ (Nascimento, 1980) e praticamente dizimou a cultura do Estado do Rio de Janeiro.

Essa praga normalmente coloniza a face abaxial das folhas e suga continuamente a seiva (dano direto). Devido à excreção de substância açucarada ("honeydew"), a infestação da cochonilha favorece o desenvolvimento do fungo Capnodium sp. As hifas desse fungo recobrem as folhas e frutos, prejudicando a respiração e a fotossíntese da planta (Cassino et al., 1991), caracterizando a fumagina.

Atualmente, essa praga encontra-se disseminada por diversas regiões do País (Fundecitrus, 2006) e não se restringe apenas àquelas produtoras de citros. Isso decorre em função do grande número de plantas hospedeiras, que incluem plantas cultivadas e daninhas, além de sua alta capacidade de reprodução (Suplicy Filho et al., 1983; Sampaio, 1987). As fêmeas não são aladas. Assim, a dispersão de $O$. praelonga pode ocorrer através do vento, bem como o transporte por meio de material de colheita (escadas e sacolas), roupas, mudas infestadas, máquinas e implementos (Carvalho, 2006), ou ainda por algumas espécies de formigas em uma relação de cooperação (Cesnik et al., 2003). Esses fatores também contribuem para o aparecimento de novos focos da praga.

Em um contexto de manejo integrado de pragas (MIP), $O$. praelonga é considerada uma praga que deve ser controlada no pomar, com nível de tolerância baixo. Como o ataque normalmente se inicia em focos, o controle desse inseto é realizado atualmente por meio de pulverizações de inseticidas na reboleira, ou seja, na

(Trabalho 156-06). Recebido em: 05-10-2006. Aceito para publicação em: 20-04-2007.

2 Departamento de Fitossanidade - UNESP/FCAV - Via de Acesso Prof. Paulo Donato Castellane, s/n. 14884-900 - Jaboticabal-SP. e-mail: oafernandes@fcav.unesp.br; tatianac@fcav.unesp.br ; apianoscki@yahoo.com.br ; thais_tanan@hotmail.com; mdacosta@fcav.unesp.br 
planta atacada e nas plantas vizinhas (Gravena, 1984). A sugestão de controle nas plantas vizinhas decorre de relatos de que essa praga pode ser disseminada por equipamentos e implementos agrícolas utilizados na citricultura (Benvenga, 2002). Todavia, esses relatos foram baseados em observações. Portanto, neste trabalho, objetivou-se avaliar o efeito de equipamentos de pulverização comumente utilizados pelos citricultores para controle de pragas dos citros na dispersão de $O$. praelonga. Essa informação é imprescindível para aprimoramento das operações de pulverização contra as diversas pragas e, conseqüentemente, do MIP citros.

\section{MATERIAL E MÉTODOS}

O estudo foi conduzido em um talhão de citros (Citrus sinensis var. Valência), plantada no espaçamento 7 x 4m, que apresentava plantas altamente infestadas por $O$. praelonga $(>$ 10 insetos/folha). Plantas infestadas, inclusive com presença de fumagina, e isoladas de outras plantas infestadas num raio de, pelo menos, $22 \mathrm{~m}$ foram previamente selecionadas.

Armadilhas adesivas amarelas (Biocontrole Métodos de Controle de Pragas Ltda.) foram instaladas para captura de insetos $(10 \times 20 \mathrm{~cm})$, tanto sobre o solo, como em vergalhões de $5 \mathrm{~m}$ de altura, em cinco posições distintas para cada uma das três linhas adjacentes à linha da planta infestada. $\mathrm{Na}$ linha, adotaram-se três plantas consecutivas, sendo que a segunda planta estava no alinhamento da planta infestada. Com isso, os vergalhões foram instalados à frente das três plantas e entre elas, que corresponderam às cinco posições de interceptação dos insetos. Em cada posição, foram instaladas quatro armadilhas adesivas sobre o solo na entrelinha enquanto, no vergalhão, instalaramse 10 armadilhas adesivas (Figura 1). Desse modo, foram instaladas 70 armadilhas adesivas, sendo 20 armadilhas (quatro em cada posição) no solo e 50 armadilhas nos vergalhões (dez em cada posição) em cada linha adjacente. Essas armadilhas foram fixadas a cada $0,5 \mathrm{~m}$ de distância.

Os tratamentos consistiram nos diferentes equipamentos utilizados normalmente para controle de pragas dos citros (Tabela 1), que se encontram descritos abaixo e cujas características de aplicação foram registradas. As aplicações foram realizadas de acordo com os padrões normalmente adotados pelos citricultores, porém utilizando-se apenas de água e pulverizando-se apenas um dos lados da planta. Cada planta pulverizada constituiu-se em uma repetição.

Os equipamentos utilizados foram:

1. Pistola Manual (Pulverizador de arrasto e manual, tratorizado): equipamento cuja calibração do fluxo de líquido e do jato de calda produzido por energia hidráulica é feita em manoplas diretamente no acessório que está à mão do operador.

2. Pistola Mecânica (Pulverizador de arrasto, tratorizado): neste equipamento, um conjunto de pistolas de pulverização de energia hidráulica é instalado numa torre na própria estrutura do pulverizador, sendo movimentadas por um motor próprio entre 20 e $45^{\circ}$ na vertical (para cima e para baixo), simulando os movimentos que o operador faria no solo, trabalhando com a pistola manual. Também há um conjunto de pontas de pulverização num barra que é arrastada sob a copa das plantas 3. Turbo Valência (Pulverizador de arrasto, tratorizado, de jato transportado): equipamento no qual o jato de pulverização é produzido em uma barra vertical que suporta uma série de pontas de pulverização de energia hidráulica. A barra é instalada na caixa de saída de vento produzido por um ventilador axial.

4. Martignani (Pulverizador tratorizado de jato transportado): equipamento dotado de um ventilador radial, cuja caixa de condução do vento é dividida em quatro saídas posicionadas e direcionadas de maneira geral para a lateral inferior e superior da copa das plantas. O jato de pulverização é produzido por bocais de energia gasosa instalados nas saídas da caixa do ventilador. 5. Bié (Pulverizador de arrasto, tratorizado de jato transportado): neste equipamento, as pontas de pulverização de energia hidráulica são instaladas nas pás do ventilador de tal forma que a movimentação do conjunto atua na formação e na distribuição das gotas.

A avaliação da dispersão foi realizada por meio da contagem de fêmeas, ninfas ou partes dos insetos (fragmentos de cera) aderidas às armadilhas adesivas instaladas. Essa contagem foi realizada imediatamente após a pulverização por meio da retirada das armadilhas, observação e registro da presença dos insetos ou partes. Foi adotado o delineamento inteiramente casualizado, com três repetições, sendo que os dados foram analisados considerando o esquema fatorial $5 \times 3$ (equipamentos x linhas da cultura) ou 5 x 3 (posições de instalação dos conjuntos de armadilhas adesivas $x$ linhas da cultura). Os dados foram transformados em $\sqrt{x+0,5}$. Essa transformação foi utilizada para normalizar os dados e estabilizar a variância. Realizaram-se análise de variância dos dados e a comparação das médias, pelo teste de Tukey, utilizando LSMEANS do procedimento PROC GLM (SAS Institute, 2001)

\section{RESULTADOS E DISCUSSÃO}

Insetos vivos (formas jovens e adultos da cochonilha) foram encontrados aderidos às armadilhas localizadas na primeira e segunda entrelinhas, somente após pulverização da planta infestada utilizando os equipamentos Bié, Martignani e Turbo Valência (Tabela 2). Todavia, a quantidade de insetos observados na segunda entrelinha foi significativamente menor do que a observada na primeira entrelinha após a utilização dos equipamentos Bié e Martignani.

Adultos (fêmeas) foram coletados em armadilhas adesivas localizadas no solo apenas na primeira entrelinha e somente quando o equipamento Bié foi utilizado. Por outro lado, ninfas foram encontradas na primeira e segunda entrelinhas, tanto nas armadilhas dispostas no solo como naquelas instaladas sobre os vergalhões (posição vertical) localizados na periferia das copas das plantas (Figura 2). Nenhum inseto foi coletado na terceira entrelinha, embora fragmentos de cera tenham sido observados nesta posição após utilização do equipamento Turbo Valência. Isto sugere que eventualmente ninfas, que são mais leves do que as fêmeas, poderiam ser arremessadas ou arrastadas pelo vento a mais de $20 \mathrm{~m}$. Avaliação do peso dos insetos indicou que as ninfas de $O$. praelonga pesam em média $0,521 \mathrm{mg}$, enquanto as 
fêmeas adultas pesam, em média, 2,237mg. Ou seja, as ninfas são quatro vezes mais leves do que as fêmeas, o que poderia facilitar seu deslocamento pelos equipamentos que produzem vento.

Observou-se ainda que a alta velocidade do vento produzido por alguns desses equipamentos causou o deslocamento de folhas infestadas que estavam no solo sob a copa da planta, bem como causou a remoção de folhas infestadas das plantas. Com isso, essas folhas infestadas e, conseqüentemente, os insetos puderam ser deslocados por, pelo menos, $20 \mathrm{~m}$ da planta infestada. Isso demonstra a importância dos equipamentos de pulverização no manejo integrado de $O$. praelonga, bem como justifica o aprimoramento dos atuais sistemas de amostragem e controle da praga considerando a reboleira, principalmente nos pomares em que a praga é importante e há uso constante de equipamentos que produzem vento como meio para aplicação de produtos fitossanitários.

O vento pode exercer forte influência na disseminação de insetos (Silveira Neto et al., 1976). Assim, a despeito da pressão utilizada, os equipamentos dotados de lança manual e que, portanto, não utilizam o vento para o transporte das gotas não causaram deslocamento de adultos, ninfas ou fragmentos cerosos de $O$. praelonga (Tabela 2 ).

A avaliação da posição das plantas adjacentes à planta infestada indicou que todas podem ser alvos de infestação por $O$. praelonga a partir do deslocamento causado pelos equipamentos Bie, Martignani e Turbo Valência (Tabela 3). Todavia, as armadilhas adesivas instaladas no solo e nos vergalhões das plantas localizadas na linha adjacente e posicionadas à frente da planta infestada apresentaram número de insetos aderidos significativamente maior (Tabela 3). Portanto, isso sugere que a probabilidade de aumento do tamanho da reboleira a partir de uma planta infestada é alta após a pulverização. Isso pode eventualmente explicar o insucesso no manejo da praga, uma vez que a utilização de equipamentos que produzem vento são freqüentemente utilizados para o controle de outros insetos, ácaros fitófagos, fungos fitopatogênicos e até para aplicação de fertilizantes foliares. Destaca-se, entretanto, que a aplicação de inseticida, mesmo para controle de outras pragas, pode, eventualmente, afetar a população de $O$. praelonga.

Portanto, evidenciou-se que mesmo a utilização de equipamentos para controle de outras pragas pode favorecer a dispersão de $O$. praelonga em pomares de citros. Embora tenha sido detectado um número muito reduzido de adultos (fêmea) nas armadilhas de solo (Figura 2 B) e nenhum adulto (fêmea) nas armadilhas dispostas nos vergalhões (Figura 2 A), a remoção de folhas infestadas nas plantas e/ou o deslocamento de folhas infestadas sobre o solo permitem que os adultos e ninfas sejam deslocados para plantas adjacentes. Ainda, com a presença de plantas invasoras sob a copa dessas plantas, pode-se favorecer a sobrevivência da praga, garantindo a infestação futura das plantas cítricas, pois $O$. praelonga possui capacidade de adaptação a mais de 141 espécies vegetais (Cassino et al., 1991), dentre as quais, diversas plantas invasoras (Nascimento et al., 1993).

Uma conformação dos equipamentos visando apenas à planta-alvo através de uma melhor adequação à silhueta das plantas, permitiria um melhor direcionamento do jato de calda e de vento, com possíveis reduções na energia para aplicação de produtos fitossanitários e redução no impacto de dispersão da praga.

TABELA 1 - Equipamentos avaliados na dispersão de Orthezia praelonga em pomar de citros.

\begin{tabular}{|c|c|c|c|c|c|c|c|}
\hline \multirow{2}{*}{ Equipamento } & \multirow{2}{*}{ Fabricante/Marca } & \multirow{2}{*}{ Tração } & \multirow{2}{*}{ Marcha } & \multirow{2}{*}{$\begin{array}{c}\text { Rotação } \\
\text { (rpm) }\end{array}$} & \multirow{2}{*}{$\begin{array}{c}\text { Velocidade } \\
(\mathbf{k m} / \mathbf{h})\end{array}$} & \multicolumn{2}{|c|}{ Fluxo de Ar (Vento) } \\
\hline & & & & & & $(\mathbf{m} / \mathbf{s})$ & $(\mathrm{km} / \mathrm{h})$ \\
\hline Pistola Manual & FMC & MF275 & 1a. Red. & 1200 & 1,5 & - & - \\
\hline Pistola Mecânica & - & MF275 & 2a. Av. & 1600 & 4,0 & - & - \\
\hline Turbo Valência & Jacto Airbus & MF5000 & 2a. Red. & 1900 & 1,5 & 18,0 & 64,80 \\
\hline Martignani & Martignani & Valmet & 1a. Red. & 1900 & 1,5 & 7,8 & 28,08 \\
\hline Bié & Bié & MF275 & 1a. Red. & 2100 & 1,5 & 16,1 & 57,96 \\
\hline
\end{tabular}

TABELA 2 - Número médio de insetos (adultos + ninfas) de Orthezia praelonga ( \pm EPM) coletados em armadilhas adesivas dispostas em vergalhões e no solo entre as linhas de citros, após a pulverização com diferentes equipamentos.

\begin{tabular}{cccc}
\hline & \multicolumn{3}{c}{ Número médio de insetos } \\
\cline { 2 - 4 } Equipamento & 1a. linha & 2a. linha & $\mathbf{3}^{\mathbf{a}}$. linha \\
& $\mathbf{( 6 - 8 ~} \mathbf{m}$ do equipamento) & $\mathbf{( 1 3 - 1 5} \mathbf{~ m ~ d o ~ e q u i p a m e n t o ) ~}$ & $\mathbf{( 2 0 - 2 2}$ m do equipamento) \\
\hline Bié & $10,00 \pm 2,08 \mathrm{Aa}$ & $1,33 \pm 1,33 \mathrm{Ba}$ & $0,00 \pm 0,00 \mathrm{Ba}$ \\
Martignani & $5,00 \pm 1,53 \mathrm{Aa}$ & $0,67 \pm 0,67 \mathrm{Ba}$ & $0,00 \pm 0,00 \mathrm{Ba}$ \\
Pistola Manual & $0,00 \pm 0,00 \mathrm{Ab}$ & $0,00 \pm 0,00 \mathrm{Aa}$ & $0,00 \pm 0,00 \mathrm{Aa}$ \\
Pistola Mecânica & $0,00 \pm 0,00 \mathrm{Ab}$ & $0,00 \pm 0,00 \mathrm{Aa}$ & $0,00 \pm 0,00 \mathrm{Aa}$ \\
Turbo Valência & $4,00 \pm 1,00 \mathrm{Aa}$ & $1,00 \pm 1,00 \mathrm{Aa}$ & $0,00 \pm 0,00 \mathrm{Ba}$ \\
\hline
\end{tabular}

Médias seguidas pela mesma letra, maiúscula na linha e minúscula na coluna, não diferem significativamente entre si, pelo Teste de Tukey (P $\leq 0,05)$. Os valores apresentados são referentes aos dados originais, embora tenham sido transformados em $\sqrt{x+0,5}$ para análise estatística. 
TABELA 3 - Número médio de insetos (adultos + ninfas) de Orthezia praelonga ( \pm EPM) coletados em armadilhas adesivas dispostas em vergalhões e no solo entre as linhas de citros, após a pulverização com os equipamentos que produzem vento (Bie, Martignani e Turbo Valência).

\begin{tabular}{|c|c|c|c|}
\hline \multirow[b]{2}{*}{ Posição do Poste } & \multicolumn{3}{|c|}{ Número médio de insetos } \\
\hline & $\begin{array}{c}\text { 1a. linha } \\
\text { (6-8 } \mathrm{m} \text { do equipamento) }\end{array}$ & $\begin{array}{c}\text { 2a. linha } \\
\text { (13-15 } \mathrm{m} \text { do equipamento) }\end{array}$ & $\begin{array}{c}3^{\mathrm{a}} \text {. linha } \\
(20-22 \mathrm{~m} \text { do equipamento) }\end{array}$ \\
\hline 1 (planta à direita) & $0,33 \pm 0,17 \mathrm{Ab}$ & $0,11 \pm 0,11 \mathrm{Aa}$ & $0,00 \pm 0,00 \mathrm{Aa}$ \\
\hline 2 (entre plantas - à direita da planta infestada) & $0,44 \pm 0,29 \mathrm{Ab}$ & $0,11 \pm 0,11 \mathrm{Aa}$ & $0,00 \pm 0,00 \mathrm{Aa}$ \\
\hline 3 (em frente à planta infestada) & $2,33 \pm 0,69 \mathrm{Aa}$ & $0,33 \pm 0,24 \mathrm{Ba}$ & $0,00 \pm 0,00 \mathrm{Ba}$ \\
\hline 4 (entre plantas - à esquerda da planta infestada) & $2,00 \pm 0,80 \mathrm{Aa}$ & $0,22 \pm 0,22 \mathrm{Ba}$ & $0,00 \pm 0,00 \mathrm{Ba}$ \\
\hline 5 (planta à esquerda) & $1,22 \pm 0,43 \mathrm{Aab}$ & $0,22 \pm 0,15 \mathrm{Aa}$ & $0,00 \pm 0,00 \mathrm{Aa}$ \\
\hline
\end{tabular}

Médias seguidas pela mesma letra, maiúscula na linha e minúscula na coluna, não diferem significativamente entre si, pelo Teste de Tukey (P $\leq 0,05)$. Os valores apresentados são referentes aos dados originais, embora tenham sido transformados em $\sqrt{x+0,5}$ para análise estatística.

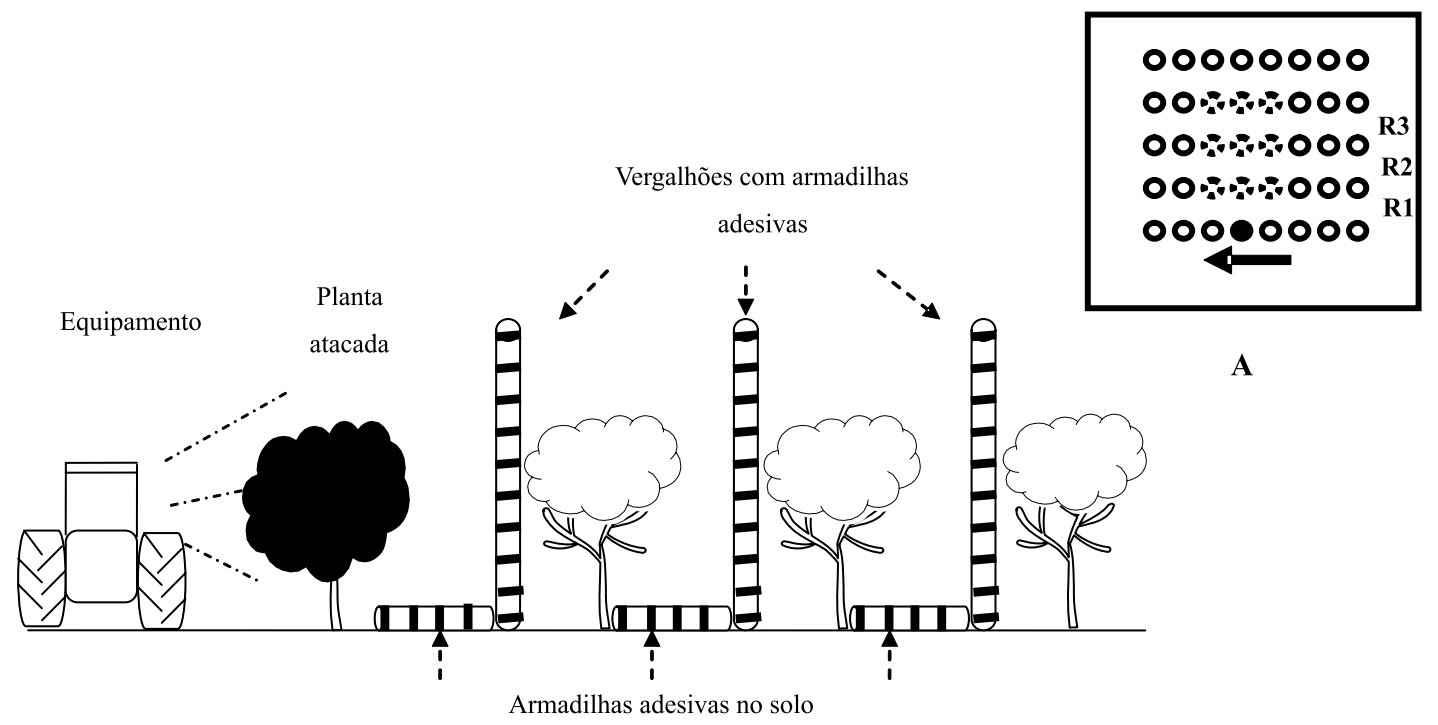

FIGURA 1 - Esquema da localização das armadilhas adesivas dispostas no solo (entrelinha) e nos vergalhões ao lado das plantas. (A) croqui da localização da planta atacada $(\bullet)$, linhas adjacentes (R1, R2 e R3) e plantas ( $)$ nas quais foram instaladas armadilhas adesivas e sentido do deslocamento do equipamento $(\leftarrow)$.
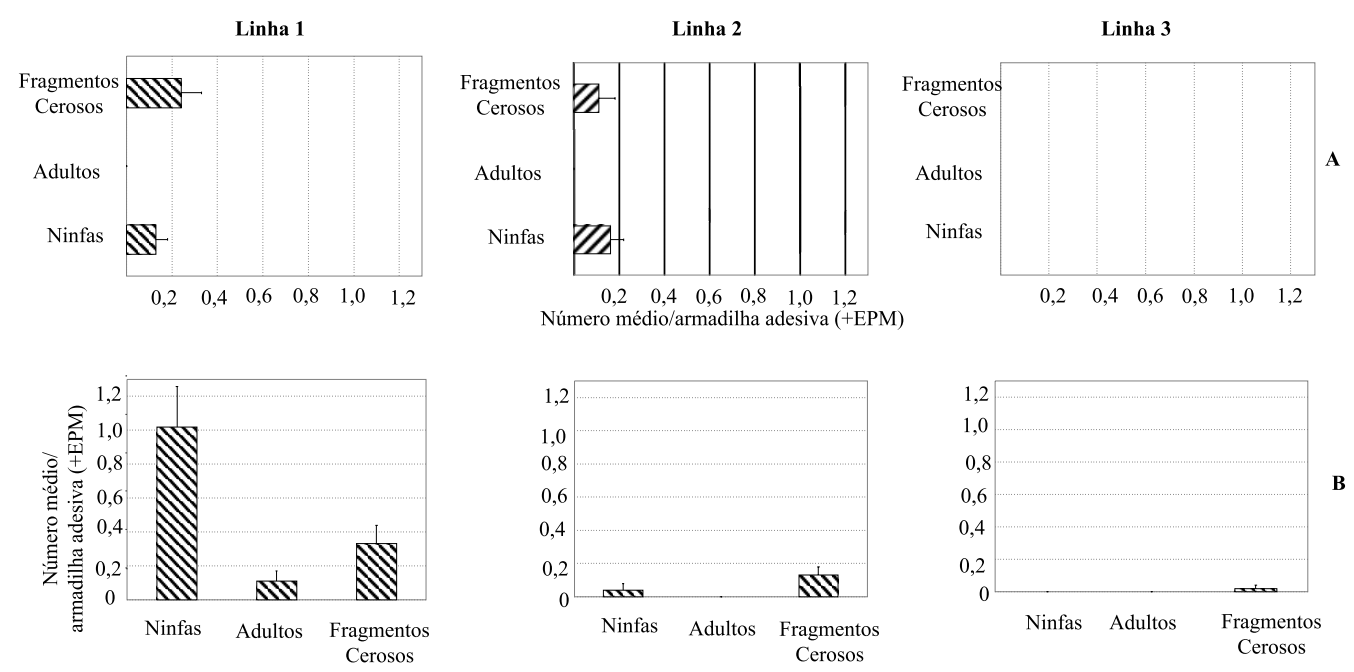

FIGURA 2 - Formas jovens, adultos e fragmentos cerosos de Orthezia praelonga coletados em armadilhas adesivas dispostas em vergalhões (posição vertical) (A) ou solo (posição horizontal) (B) nas linhas 1 a 3 adjacentes àquela que continha a planta infestada e pulverizada após a pulverização com os equipamentos que produzem vento (Bie, Martignani e Turbo Valência). 


\section{CONCLUSÃO}

Os pulverizadores tratorizados que utilizam vento, favorecem a dispersão de ninfas e adultos de $O$. praelonga durante a aplicação de produtos fitossanitários.

\section{AGRADECIMENTOS}

Os autores são agradecidos ao Fundecitrus - Fundo de Defesa da Citricultura, pelo auxílio financeiro, e à Cambuhy Agrícola Ltda. pelo apoio logístico para a instalação e condução do projeto.

\section{REFERÊNCIAS}

BENVENGA, S. R. Manejo da cochonilha ortézia em pomares cítricos. Ciência e Prática, Lavras, v.2, n.5, 2002.

CARVALHO, R. S. da. Sugador Mortal. Cultivar HF, Pelotas, n.35, p.16-19, 2006.

CASSINO, P.C.R.; LIMA, A.F.; RACCA FILHO, F. Orthezia praelonga Douglas, 1891 em plantas cítricas no Brasil. Arquivos da UFRJ, Rio de Janeiro, v.14, p.27-34, 1991.

CESNIK, R.; PRATES, H. S.; ALVES, S. B. Controle biológico da cochonilha ortézia. Disponível em: <http:// www.cati.sp.gov.br/novacati/index.php>.Acesso em: 05 jan. 2006.

FUNDECITRUS. Fundo de defesa da citricultura. Disponível em: $<$ http://www.fundecitrus.br>. Acesso em: 05 jan. 2006.

GONÇALVES, C.R.; CASSINO, P.C.R. O problema da Orthezia praelonga na citricultura. In: ENCONTRO NACIONAL DE CITRICULTURA, 1978, Rio de Janeiro. Anais... p.5.

GRAVENA, S. Manejo integrado de pragas do citros. Laranja, Cordeirópolis, n.5, p. 323-362, 1984.

NASCIMENTO, A.S. Ecologia da Orthezia praelonga Douglas, 1891 (Homoptera: Ortheziidae) na região de Cruz das Almas - BA. Cruz das Almas: EMBRAPA, 1980. 4p. (Comunicado Técnico, 9)

NASCIMENTO, A. S.; PERRUSO, J. C.; CASSINO, P. C. R. Novos hospedeiros de Orthezia praelonga Douglas, 1891 (Homoptera: Ortheziidae). Anais da Sociedade Entomológica do Brasil, Piracicaba, v. 22, n. 1, p. 213-215, 1993.

SAMPAIO, A.C. Bioecologia e controle da cochonilha Orthezia praelonga Douglas, 1891 (Homoptera: Ortheziidae) através de inseticidas e óleos minerais. 1987. 102 f. (Trabalho de Graduação - Agronomia) - Faculdade de Ciências Agrárias e Veterinárias, Universidade Estadual Paulista, Jaboticabal-SP. 1987.

SAS INSTITUTE. Stat users guide, release 8.0 ed. SAS Institute, Cary, NC. 2001

SILVEIRANETO, S.; NAKANO, O.; BARBIN, D.; VILLANOVA, N. A. Manual de ecologia dos insetos. Piracicaba: Ed. Ceres, 1976. 419p.

SUPLICY FILHO, N.; SAMPAIO, A.S.; MYAZAKI, I. Considerações sobre o coccídeo Orthezia praelonga, Douglas, 1891, importante praga da citricultura brasileira. O Biológico, São Paulo, v. 49, p. 19-24, 1983. 